\title{
Multi-level responses of Macoma balthica to recurring hypoxic disturbance
}

\section{Villnäs, Anna}

2019-01

Villnäs , A , Norkko , A \& Lehtonen , K K 2019 , ' Multi-level responses of Macoma balthica to recurring hypoxic disturbance ' , Journal of Experimental Marine Biology and Ecology , vol. 510 , pp. 64-72 . https://doi.org/10.1016/j.jembe.2018.10.005

http://hdl.handle.net/10138/323946

https://doi.org/10.1016/j.jembe.2018.10.005

CC BY-NC-ND

acceptedVersion

Downloaded from Helda, University of Helsinki institutional repository.

This is an electronic reprint of the original article.

This reprint may differ from the original in pagination and typographic detail.

Please cite the original version. 
1 This is the AUTHORS' ACCEPTED MANUSCRIPT, for the published article, please see:

2 https://doi.org/10.1016/j.jembe.2018.10.005

3

4 Full citation:

5 Villnäs A, Norkko A, Lehtonen KK (2019) Multi-level responses of Macoma balthica to recurring

6 hypoxic disturbance. Journal of Experimental Marine Biology and Ecology 510: 64-72.

7

8

9 Multi-level responses of Macoma balthica to recurring hypoxic disturbance

Anna Villnäs ${ }^{1 *}$, Alf Norkko ${ }^{1,2}$, Kari K. Lehtonen ${ }^{3}$,

13 1'Tvärminne Zoological Station, University of Helsinki, J. A. Palménin tie 260, FI-10900 Hanko,

14 Finland

$15 \quad{ }^{2}$ Baltic Sea Centre, Stockholm University, SE-106 91 Stockholm, Sweden

16 3Finnish Environment Institute, Marine Research Centre, Agnes Sjöbergin katu 2, FI-00790

17 Helsinki, Finland

18

19 *Corresponding author; Anna Villnäs

20

e-mail: anna.villnas@helsinki.fi, phone:+358 503119371

21 
23 Abstract

24 The frequency of seasonal and short-term hypoxia is increasing in coastal seas. How such repeated disturbances affect key species that have important roles for ecosystem processes and functions remains, however, unknown. By performing a field experiment we explored if the bivalve Macoma balthica can cope with short-term, recurring hypoxic stress, and investigated how hypoxia affects the condition of surviving bivalves. By combining data on different levels of biological organization, i.e., on physiology (biomarker response), behaviour and demography, we identified stress responses before the population declined. One pulse of hypoxic disturbance (3 days) resulted in behavioural alterations, as adult M. balthica extended their siphons, emerged towards the sediment surface and expressed decreased reburial rates. However, the demographic structure of the population remained unaltered. Several pulses of recurring hypoxic stress resulted in physiological response with changes in glutathione reductase and acetylcholinesterase enzyme activities. The recurring hypoxic disturbance was observed to affect juvenile bivalves before adults, while prolonged hypoxia reduced the entire bivalve population. Our results clearly show that hypoxic stress changes the behaviour and physiology of M. balthica before demographic changes occur, which is likely to have severe implications for the contribution of this key species to ecosystem functioning. That a combination of measures at different levels of organization can detect disturbances at an early stage suggests that such an approach would be useful for assessing the effects of disturbances on marine ecosystems that are increasingly affected by anthropogenic change.

\section{Highlights}

- recurring hypoxia induces stress responses at multiple levels in Macoma balthica

- behavioural and physiological change precede alterations in size structure

- antioxidant defence system of M. balthica is activated by hypoxic stress

- juveniles are more sensitive than adults towards recurring hypoxia

Key words: Macoma balthica; biomarkers; behaviour; demography; hypoxia; Baltic Sea. 


\section{Introduction}

The Baltic clam, Macoma balthica (L.), plays a key role in ecosystem processes in the northern Baltic Sea, where no other species can fully replace its important functions (Norkko et al. 2013). This facultative deposit- and suspension-feeder constitutes an important link in the benthic food web, serving as a prey organism for benthivorous fish (e.g., flatfish Platichthys flesus and gobies Pomatoschistus spp.) and invertebrate predators (Saduria entomon and Crangon crangon; Aarnio and Bonsdorff 1993, Bonsdorff et al. 1995). Furthermore, as a biodiffuser it reworks and irrigates the sediment, hence contributing to essential ecosystem functions such as organic matter mineralization, sediment oxygenation and nutrient recycling (Michaud et al. 2005, 2006, Volkenborn et al. 2012, Norkko et al. 2013). Through its activities, M. balthica also acts as a facilitator, stimulating the growth of microorganisms and diatoms in surface and subsurface sediment layers (Reise 1983). The species has a wide geographic distribution throughout temperate and arctic coastal waters in the northern hemisphere (Caddy 1967, Gilbert 1973). It tolerates a wide range of physical conditions due to genetic adaptation and hybridization (Hummel et al. 1995, 1997, Nikula et al. 2008). In terms of abundance and biomass, it is often the dominating species of benthic communities in the brackish Baltic Sea until its salinity limit is reached (ca 3; Nikula et al. 2008). In this shallow sea, M. balthica occurs on soft bottoms from 3 to $200 \mathrm{~m}$ depth (Segerstråle 1965). However, its contributions to ecosystem functions in this sea area is increasingly threatened by the occurrence of bottom-water hypoxia.

Hypoxia $\left(\mathrm{O}_{2}<2 \mathrm{ml} \mathrm{l}^{-1}\right)$ is an important factor structuring the benthic communities in both open and coastal areas of the Baltic Sea (Karlson et al. 2002, Carstensen 2014, Gammal et al. 2017). Hypoxia is often the result of eutrophication, i.e., excess anthropogenic input of nutrients and organic matter, but it is also exacerbated by physical factors such as vertical stratification of the water column caused by haloclines or thermoclines which are most pronounced during summer time. Alarmingly, the frequency of seasonal and short-term hypoxic events has been reported to increase in coastal areas of the Baltic Sea (Conley et al. 2011). Sediment-dwelling bivalves are quite resistant to hypoxia, and are often the last ones to disappear as hypoxia strikes (VaquerSunyer \& Duarte 2008). Adult M. balthica are known to withstand hypoxia for several weeks of experimental exposure (Jahn and Theede 1997, Modig and Ólafsson, 1998, Long et al. 2008) and from days to week(s) in nature (Norkko and Bonsdorff 1996a, Villnäs et al. 2012). Still, there is limited information regarding the tolerance of juvenile $M$. balthica towards hypoxic stress, but results of Jansson et al. (2015) indicate that they have a capability to survive hypoxia in experimental conditions at least 29 days. The small, early life-stages (larvae and post-settlement 
stages) of $M$. balthica can rapidly colonize disturbed patches and thus be vital for community recovery after hypoxic disturbance cease (Valanko et al. 2010). On the other hand, if hypoxia eliminates the adult individuals, their limited mobility and long generation time (commonly 5-10 years, but even up to 30 years; Segerstråle 1960, Gilbert 1973) will prevent development of viable populations (Norkko et al. 2013). In places exposed to frequent hypoxic disturbance there is a risk that $M$. balthica becomes functionally extinct as the bivalves might never reach a full adult size and be able to contribute to essential ecosystem functions (Norkko et al. 2013).

It remains unknown whether $M$. balthica has a potential to adapt to short-term recurring hypoxic stress, and how hypoxia affects the condition of the surviving bivalves. When exposed to oxygen deficiency, bivalves can change their physiology and conserve energy through a slowdown of metabolic rates and through growth reduction. Behavioural changes can be seen as stretched-out siphons, reduced burrowing depths, or movement from burrows onto the sediment surface (Villnäs et al. 2012). However, such physiological and behavioural changes are preceded by responses at the molecular level and altered gene expression (e.g. Wu 2002, Sussarellu et al. 2012, Yusseppone et al. 2018). Changes in oxygen levels lead to a generation of reactive oxygen species (ROS) and animals exposed to repeated hypoxic disturbance must cope with the phenomenon called oxidative stress (Welker et al. 2013), which can have also many other inducing factors, including exposure to various contaminants (Livingstone 2001). Induction of oxidative stress as a response to limited oxygen availability has been reported in various organisms (Hermes-Lima and Zenteno-Savín 2002, Zenteno-Savín et al. 2006, Lushchak 2011). When the amount of ROS exceeds the antioxidant buffering capacity of an organism, damage to major biomolecules occurs (proteins, lipids and DNA; Gorokhova et al. 2013, Welker et al. 2013).

To evaluate the health of a population or a community it is useful to combine data on disturbance effects at different levels of biological organization (Broeg and Lehtonen 2006). Indeed, by examining disturbance effects on physiology, behaviour and demography, stress responses can be detected prior to population declines. Biomarkers are quantitative measures of changes in an organism on a cellular, biochemical, molecular or physiological level that respond to contaminants with harmful biological effects, but also to changes in metabolism and variations in the environment (Lam and Gray 2003, Barda et al. 2014). As biomarkers can detect disturbance effects at the biochemical level they may provide an early warning signal of deleterious changes in the organisms' health. Still, biomarkers have rarely been used to complement measures of population behaviour and structure (e.g., abundance, biomass, demography) in field experiments assessing the effects of disturbances, which could be useful to obtain a more comprehensive assessment. 
By performing a manipulative field experiment, this study explores how recurring disturbance, in form of bottom water hypoxia, affects the condition of $M$. balthica as measured by different biomarkers, changes in behaviour, and survival. We hypothesize that increasingly recurring hypoxia will gradually increase the stress response of $M$. balthica, and that the stress response can be detected at the biochemical level before changes are observed in individual behaviour and at the population level.

\section{Material and methods}

\subsection{Physical characteristics of the experimental site}

The study site $\left(59^{\circ} 50^{\prime} 24^{\prime \prime} \mathrm{N}, 23^{\circ} 15^{\prime} 37^{\prime \prime}\right.$ E) was situated in the non-tidal brackish-water archipelago of the Gulf of Finland, northern Baltic Sea. The experiment was performed in August 2009 at $5 \mathrm{~m}$ depth. Salinity at the site was 5.8 while bottom water temperatures varied between 15 $19{ }^{\circ} \mathrm{C}$ during the experiment, due to an occasional upwelling of cold bottom water. Sandy sediments dominated the site that was characterized by an organic matter content of, on average, $1.37 \pm 0.44 \%$ (SE), a median grain size distribution (d50) of $0.12 \pm 0.01$ while the grain size proportion $<63 \mu \mathrm{m}$ was $19.88 \pm 1.75 \%$ (Villnäs et al. 2013).

\subsection{Experiment setup in situ}

Dark plastics sheets $\left(1 \mathrm{~m}^{2}\right)$ were used to induce hypoxic disturbance at the seafloor (for methods: see Villnäs et al. 2013). The dark conditions are representative of hypoxic conditions beneath drifting algal mats, or those introduced by water column stratification beneath the photic zone. The sheets were kept in place with metal rods, which were secured with $30 \mathrm{~cm}$ metal pegs to prevent water exchange. By preventing water exchange as well as primary production, standardized levels of hypoxia were introduced. There were five treatments, each replicated four times (total $N=20$ ). The four replicates of each treatment were placed in a block design along four orthogonal $17 \mathrm{~m}$ long transects, so that each block contained one replicate of each treatment. The treatments represented undisturbed sediments (C; Control), sediment exposed to 30 days of uninterrupted hypoxia (L: Long), as well as sediments exposed to increasing recurrences of short pulses of hypoxia, i.e., Repeated 1, 3 and 5 (R1, R3 and R5, respectively). Treatment R1 was exposed to three days of hypoxia. The intermittent hypoxic disturbance in treatment R3 was induced by repeating the pulse 
148

149

150

151

152

153

154

155

156

157

158

159

160

161

162

163

164

165

166

167

168

169

170

171

172

173

174

175

176

177

178

179

of short hypoxia (i.e., 3 days) three times for each replicate plot. Between the pulses of hypoxia, oxic conditions were allowed to re-establish by removing the plastic for four days. For treatment R5 there were five pulses of short hypoxic disturbance (each one again lasting 3 days), in between which oxic conditions were re-established during four days by removing the plastic. These short, recurring pulses of hypoxia represent episodic hypoxic conditions that can last from days to months and are caused by dense, drifting algal mats or by water column stratification during late summer. Episodic hypoxia is common in this sea area, and pulses of hypoxia are known to recur as weather conditions change the strength and depth of water column stratification and direct the movement of algal mats (Norkko et al. 1996b, Conley et al. 2011, Villnäs et al. 2013). The disturbance was ended simultaneously for the R1, R3, R5 and L treatment as the plastic was rolled away after the last hypoxic period. The plastic sheets have been shown to rapidly cause hypoxia; after ca 1.5 days the bottom water oxygen saturation reach $0.56 \mathrm{mg} \mathrm{O}_{2} \mathrm{l}^{-1}$, while after 3 days, $0.1 \mathrm{mg} \mathrm{O}_{2} \mathrm{l}^{-1}$ has been measured. After seven days, anoxic conditions (i.e., $\left.0 \mathrm{mg} \mathrm{O}_{2} \mathrm{l}^{-1}\right)$ and hydrogen sulphide $\left(\mathrm{H}_{2} \mathrm{~S}\right)$ formation $\left(3 \mu \mathrm{mol} \mathrm{l}^{-1}\right)$ has been observed (Villnäs et al. 2012).

After the disturbance ended, all treatments were exposed to normoxic conditions. The number of living bivalves at the sediment surface were counted and their behaviour was observed. Adult M. balthica were collected from each replicate plot for a reburial experiment $(\mathrm{N}=20$ per treatment, except for the $\mathrm{L}$ treatment where $\mathrm{N}=10$ ) while bivalves representing the control were extracted from undisturbed sediments at each transect. Bivalves for biomarker analyses $(\mathrm{N}=15$ per treatment) were collected in a similar manner. In addition, to quantify the abundance, biomass and size structure of M. balthica, quantitative samples were obtained with two replicate cores $(\varnothing 6 \mathrm{~cm}$, depth $15 \mathrm{~cm}$ ) from each plot. These cores were taken from an area of $504 \mathrm{~cm}^{2}$ that was subsequently excavated (to ca $30 \mathrm{~cm}$ depth), in order to account for any deeper-burrowing bivalves. All field manipulations and sampling were done using SCUBA.

A suite of biomarkers was used to evaluate the stress response on the molecular, biochemical and physiological levels. Specifically, catalase (CAT), glutathione reductase (GR), glutathione $S$ transferase (GST), and acetylcholinesterase (AChE) enzyme activities were used. The antioxidant enzyme CAT is responsible for the transformation of reactive oxygen species, and is expected to increase its activity under oxidative stress (Regoli and Giuliani 2014). GR and GST are important in antioxidant protection, and GST is also a key enzyme in Phase II detoxification (conjugation) of 
180

181

182

183

184

185

186

187

188

189

190

191

192

193

194

195

196

197

198

199

200

201

202

203

204

205

206

207

208

209

210

organic xenobiotics (Regoli and Giuliani 2014). Both CAT and GST activities in M. balthica have shown a positive correlation with near-bottom oxygen saturation (Leiniö and Lehtonen 2005, Barda et al. 2014). AChE, which is involved in the synaptic transmission of nerve impulses, has also been considered a useful biomarker of general physiological stress (e.g., Leiniö and Lehtonen 2005, Turja et al. 2013). After sampling, 15 adult M. balthica (length 13-19 mm) per treatment were placed in aquaria with normoxic seawater in a cold room, with temperature regulated to correspond to ambient field conditions. Dissection of these bivalves was performed a couple of hours after the sampling. The foot tissue of M. balthica was separated for analysis of AChE while the digestive glands (DG) were obtained for analysis of CAT, GR, and GST. The tissue samples were immediately frozen at $-80^{\circ} \mathrm{C}$.

AChE activity. Analyses (5 pooled replicates per treatment) of AChE activity were carried out as described in Bocquené and Galgani (1998). Pooled samples of foot tissue were homogenised in 1:2 w/v $0.02 \mathrm{M}$ phosphate buffer $(\mathrm{pH} 7.0)$ with $0.1 \%$ Triton X. The homogenates were centrifuged at $10,000 \times g$ for $20 \mathrm{~min}$ and the resulting supernatants were used for the measurements. Infinite 200 96-well microplate reader equipped with Magellan software (TECAN) were used for the spectrophotometric measurement of the Ellman reaction (Ellman et al. 1961). AChE activity is expressed as equivalents of acetylthiocholine (ACTC) hydrolysed, with $1 \Delta$ O.D. corresponding the hydrolysis of $75 \mathrm{nmol}$ of ACTC, and expressed per protein concentration of the foot tissue (nmol ACTC min $^{-1} \mathrm{mg}$ protein ${ }^{-1}$ ) measured using the Bradford (1976) method and a BSA standard.

$C A T, G R$, and GST activities. The DG samples (15 replicates) were homogenised in $100 \mathrm{mM}$ K-phosphate buffer $(\mathrm{pH} 7.4)$ and centrifuged at 10,000 $\times g$. The supernatant obtained was stored at $-80^{\circ} \mathrm{C}$ until analysis. CAT activity was measured following the method of Claiborne (1985) as CAT mediated degradation of hydrogen superoxide $\left(\mathrm{H}_{2} \mathrm{O}_{2}\right)$. GR activity determination was based on the method by Carlberg and Mannervik (1975). GST activity was determined using a method based on Habig et al. (1974). For more detailed information on final reaction concentrations and chemicals used, please see Turja et al. (2013). All enzymatic activity rates were measured using the equipment and software mentioned above and were normalized to protein content of the digestive gland. 


\subsubsection{Integration of biomarker data}

212 The Integrated Biomarker Index (IBR; Beliaeff and Burgeot 2002) is a simple tool based on the

213 standardisation of the different biomarker values and finally summing up triangular Star Plot areas

214 calculated for each two neighbouring biomarkers in a given data set. All the four biomarkers

215 measured here were used for the calculation of the IBR, which represents the average of different

216 permutations of biomarkers in each treatment. Finally, the index values are given divided by the

217 number of biomarkers used and is termed as IBR/n (Broeg and Lehtonen 2006). The IBR is not a

218 statistical analysis but summarizes the response of all individual biomarkers and can thus be useful

219 for interpreting the overall stress pattern.

220

221

222

223

224

225

226

227

228

229

230

231

232

233

234

235

236

237

238

239

240

241

\subsection{Behavioural change}

Behavioural changes were assessed by observing and counting the number of emerged bivalves at the sediment surface, and by measuring reburial rates of adult $M$. balthica in laboratory conditions. In a temperature-regulated room, 20 bivalves from each treatment (i.e., 5 per replicate plot) were put into four separate aquaria ( $35 \times 25 \times 22 \mathrm{~cm}$ ), and their reburial rates (in minutes) were measured. From the L treatment only 10 living M. balthica were found (in total), which were added to a separate compartment in the aquarium of treatment R5. The aquaria contained $5 \mathrm{~cm}$ sediment (sieved through $1 \mathrm{~mm}$ mesh) and water collected from the experiment site, with temperatures (15 ${ }^{\circ} \mathrm{C}$ ) and salinity (5.8) similar to field conditions. Oxygen concentrations were saturated throughout the reburial experiment.

\subsection{Demographic change}

Changes in abundance, biomass and size structure were used to evaluate the disturbance effect on the $M$. balthica population. The quantitative benthic samples were sieved $(0.2 \mathrm{~mm})$, preserved in $70 \%$ ethanol and stained with rose bengal, and a binocular microscope was used for species identification. All bivalves were measured, and individuals of juvenile $(<5 \mathrm{~mm})$ and adult $(>5 \mathrm{~mm})$ M. balthica were separated. M. balthica is fully developed when it reaches ca $2 \mathrm{~mm}$ size, but sexual differentiation rarely occurs in individuals smaller than $5 \mathrm{~mm}$ (Caddy 1967, 1969). The weight of juvenile and adult bivalves in each sample was determined (precision $0.1 \mathrm{mg}$ blotted wet weight, including the shells). 
243 To detect differences between treatments for biomarkers, permutational ANOVA (PERMANOVA), 244 with a posteriori pair-wise comparisons was used. Homogeneity of dispersions was evaluated with 245 the PERMDISP routine. Euclidean distances were used as the resemblance measure, calculated on 246 square root transformed values if needed to improve dispersion (Anderson et al. 2008).

247 PERMANOVA was also used for detecting differences in bivalve reburial rates, in size-frequency 248 distribution, and in the abundance and biomass of adult and juvenile M. balthica between 249 treatments. In these analyses, the L treatment (exposed to 30 days of uninterrupted hypoxia) was 250 excluded, as its impoverished population (1\% of the control) clearly differed from the other 251 treatments. The analyses were performed in PERMANOVA+ for Primer (Anderson et al. 2008).

\section{Results}

\subsection{Effects on biomarkers}

256

257

258

259

260

261

262

263

264
Biomarkers of the antioxidant defence system showed differential responses to increasingly recurring hypoxia. CAT levels showed no significant differences between the treatments (Table 1) although inter-individual variability was considerably higher in treatments R5 and L, compared to R1 and R3 (Fig. 1). The levels of GR increased significantly with recurring hypoxic stress, being about 1.5 to 2 times as high in treatments R3 and R5 compared to the $\mathrm{C}$ and R1 treatments (Fig. 1, Table 1). In the L treatment the GR activity values were similar to the control level (Fig. 1). However, some samples in the analysis of GR failed and could not be repeated either, resulting in a reduction in the number of replicates from the original 15 . No significant changes were observed in the levels of the detoxification enzyme GST (Fig. 1, Table 1). The neurotoxicity/general stress indicator AChE showed a significant decrease in treatments R1 and R3 compared to the control, but the levels were again elevated in individuals remaining from treatments R5 and L (Fig. 1, Table 1). The IBR/n index calculated using all the four biomarkers indicated that, compared to the normoxic control situation, all hypoxia treatments had a markedly negative effect on $M$. balthica, indicating an elevated integrated stress level under these conditions (Fig. 2). 
273 No bivalves were observed at the surface of undisturbed control sediments. After 3 days of hypoxic 274 disturbance (treatment R1), behavioural changes were observed in M. balthica. The siphons were 275 protruding out of the sediment and adults had emerged to the sediment surface (on average $51 \pm 6$ 276 std), but they were fast to rebury when the plastics were rolled away and oxic conditions were re277 established. The sediment was still brown in colour and only minor black spots were observed. 278 Increasingly reduced conditions were apparent for the R3, R5 and L treatments, where parts of the 279 sediment surface was black due to the formation of $\mathrm{H}_{2} \mathrm{~S}$ and precipitation of ferrosulphides. In the 280 R3 and R5 treatments a large number of bivalves had emerged on the sediment surface (on average $28151 \pm 11$ and $61 \pm 19$, respectively, Fig. 3). Numerous dead bivalves were observed at the sediment 282 surface in the L treatment (on average $239 \pm 41$ ).

283 The behavioural changes observed in the field were confirmed in the reburial experiment (Fig. 4).

284 While $75 \%$ of the bivalves in the $\mathrm{C}$ treatment reburied during the first half hour, those in the R1, R3 285 and R5 treatments were significantly slower to rebury compared to the control (Table 1, 286 PERMANOVA post hoc comparisons $\mathrm{p}<0.05$ ). The majority of the bivalves in the $\mathrm{L}$ treatment did not rebury at all (Fig. 4).

\subsection{Effects on survival and demography}

290 M. balthica was one of the dominating species in the local benthic community. Juveniles

291 contributed, on average, to $20 \%$ of community abundance in undisturbed sediments, while adult $M$.

292 balthica accounted for ca $70 \%$ of total benthic biomass. With increasingly recurring hypoxic

293 disturbance the bivalve abundance decreased, but the biomass values remained high (Fig. 5). The

294 number of juvenile M. balthica was reduced by 50\% in the R3 treatment compared to the control,

295 but due to high within-treatment variability only the R5 treatment differed significantly from the 296 control (Fig. 5, Table 1). The biomass of adult M. balthica showed a peculiar pattern since an 297 increased bivalve biomass was observed in the R1 and R3 treatments compared to the control (Fig. 298 5). The increased biomass in treatments R1 and R3 could possibly be due to the migration towards 299 the sediment surface of deep-dwelling bivalves in response to the disturbance. The number of adult 300 M. balthica in treatment R5 was significantly lower than in control sediments (Fig. 5, Table 1), 301 while in the L treatment, only a few adult individuals had survived, representing about $1 \%$ of the 302 control population. Changes in the size distribution of the M. balthica population confirmed that 303 while juveniles experienced marked reductions when exposed to three pulses of hypoxic stress (R3), 
adult individuals were able to survive several pulses of recurring hypoxia (Fig. 6). However, significant difference in size-frequency distributions was only noted for the R5 treatment compared to the others (i.e. C, R1, and R3, Table 1, PERMANOVA post hoc $\mathrm{p}<0.05$ ).

\section{Discussion}

Episodic hypoxia is prevalent in the coastal zone of the Baltic Sea (Conley et al. 2011), but the capability of benthic species to adapt to, or survive, short, recurring periods of oxygen deficiency (days-to-weeks) in in situ conditions is currently poorly known. We examined the disturbance response of a key species, $M$. balthica, by combining measures of disturbance effects at different levels of biological organization (physiological, behavioural and demographic) to investigate how hypoxia affected the bivalve population. Our results show that one pulse of hypoxic disturbance (3 days) results foremost in behavioural alterations, while the demographic structure of the population remained unaltered. Recurring hypoxic disturbance resulted in physiological (as indicated by selected biomarker responses) as well as behavioural changes. Recurring hypoxia was observed to affect juvenile bivalves before adults, while increasingly recurring or pro-longed hypoxic stress resulted in an increasingly reduced bivalve population. Our results clearly show that hypoxic stress changes the behaviour and physiology of M. balthica before demographic changes occur, which is likely to have severe implications for the contribution of this key species to ecosystem functioning (Villnäs et al. 2012, 2013, Norkko et al. 2013).

Biomarker responses give information on the biochemical and physiological phenomena underlying the health condition of individuals in a population and the capacity of protective measures at the cellular level. In the absence of stressful conditions, such as our control treatment, ROS generated in the cell are effectively neutralized and removed by the antioxidant defense system (ADS) in healthy animals (Livingstone 2001, Fernandez et al. 2010). Many stress factors increase ROS production and may overwhelm the antioxidant capacity or decrease the function of the ADS, leading to excessive ROS formation and oxidative damage to DNA, proteins and lipids (Livingstone 2001). Adult M. balthica, exposed to one pulse (3 days; R1 treatment) of hypoxic stress exhibited behavioural change in the form of extended siphons and emergence on sediment surface, a behaviour that has previously been reported for bivalves exposed to oxygen deficiency (Diaz and Rosenberg 1995 Gray et al. 2002, Riedel et al. 2008, Levin et al. 2009, Villnäs et al. 2012). However, these individuals expressed no significant changes in biomarker levels 
336 indicative of increased ROS formation. Interestingly, Rivera-Ingraham et al. (2013) explored in

337 laboratory conditions how short-term hypoxia and anoxia ( 24 to 72 hours; corresponding to our R1

338 treatment) and subsequent re-oxygenation affected ROS and the condition of the gill and mantle

339 tissues in intertidal blue mussels, Mytilus edulis. The authors found that ROS concentrations

340 decreased during anoxic exposure but increased in response to re-oxygenation. Still, the mussels did

341 not suffer major oxidative stress in the gill and mantle tissues (Rivera-Ingraham et al. 2013).

342 Unfortunately, this study did not explicitly measure metabolic rate depression (MDR), which is a

343 common mechanism in organisms to save energy also during hypoxic conditions. MDR leads to a

344 decreased production of ROS, which subsequently reduces the demand on antioxidant production

345 and ADS in general (Guppy and Withers 1999, Welker et al. 2013). Interestingly, for the bivalve

346 Arctica islandica, Philipp et al. (2012) noted suppression in the expression of several stress-related

347 genes, including some related to metabolism, under hypoxia in a German Bight (North Sea)

348 population while the opposite (upregulation) was recorded for a Baltic Sea population. The authors

349 suggested that MDR is not a strategy for the latter population, and bivalves chronically exposed to

350 high environmental variability (oxygenation, temperature, salinity), e.g. in the Baltic Sea, might

351 have higher physiological flexibility and ability to withstand stress by exhibiting a pronounced

352 stress response as a trade-off with a longer life span brought up by MDR.

In contrast to the $\mathrm{C}$ and $\mathrm{R} 1$ treatments, recurring oxygen deficiency (treatments $\mathrm{R} 3$

354 and R5) resulted in significantly increased GR levels in adult bivalves compared to the control. GR

355 is an enzyme that catalyses the reduction of glutathione (GSH), a process that activates this critical

356 molecule to resist oxidative stress. An increase in ROS during hypoxia has been suggested to serve

357 as a "preparation for oxidative stress" by activating antioxidant enzymes that minimize oxidative

358 damage during re-oxygenation (Gorokhova et al. 2013, Welker et al. 2013). In the present study, the

359 measured biochemical responses were mirrored in behavioural changes, as many of the surviving

360 adult bivalves exposed to repeatedly occurring hypoxia (R3, R5) were found with elongated siphons

361 and sometimes open valves at the sediment surface. Importantly, since parts of the adult individuals

362 were removed from the system during the course of the experiment due to predation or death, the

363 sampled individuals probably represent the more tolerant part of the population. Indeed, in the R5

364 treatment, only $40 \%$ of the adult $M$. balthica population was still alive. The elevated GR activity in

365 the R3 and R5 treatments indicated that these individuals were stressed but able to compensate by

366 active production of GSH. The increased GR activity indicates an elevated requirement for GSH,

367 which is an indispensable co-factor for a number of defence enzymes as well as an important

368 antioxidant molecule itself (Regoli and Giuliani 2014). Increased concentrations of GSH have been 
369

recorded in the digestive gland tissue of bivalves experimentally exposed to hypoxia (Khan and Ringwood 2016), likely induced by an increased production of the molecule by the specific synthesising enzymes and/or by increased GR activity processing the oxidized GSSG back to the reduced form. Although GSH/GSSG was not measured in this study, the results indicate that at least the latter mechanism is apparently functioning in M. balthica from the Baltic Sea. Still, in the R5 treatment, an elevated AChE activity back to the control level indicated that the condition of the animals had improved; however, this can be due to the fact that the measurements were carried out in the tolerant, surviving population and the situation could have been different if the measurements would have been done a bit earlier when ca $60 \%$ of the population was approaching a critical condition and about to die. Indeed, in the $\mathrm{L}$ treatment (after 30 days of continuous stress) only about $1 \%$ of the adult $M$. balthica was recorded alive, undoubtedly the most tolerant individuals; in these, the GR activity had already started to decline, indicating the bell-shape stress response pattern typical for antioxidant defence system enzymes (Regoli and Giuliani 2014), while AChE activity was just short of being significantly lower than in the control treatment. In both the R5 and the L treatment, the increased stress was also reflected in the high variability in CAT activity in the surviving individuals, but throughout our experiment, levels of GST remained unchanged.

The variable stress response indicate that individuals differ in their tolerance levels and capacity for surviving hypoxia. However, Jahn and Theede (1997) showed that adult $M$. balthica exhibited small differences in lethal time ( $\left.\mathrm{LT}_{50}\right)$ in response to oxygen deficiency (8-12 days). In our case, the formation of $\mathrm{H}_{2} \mathrm{~S}$ and ammonia caused additional stress as the hypoxic disturbance progressed, especially in the R5 and L treatments. $\mathrm{H}_{2} \mathrm{~S}$ is toxic and needs to be detoxified or excluded from the animal to enable survival. Populations of adult M. balthica have shown different degrees of $\mathrm{H}_{2} \mathrm{~S}$ tolerance, suggesting that some specimens are able to oxidize $\mathrm{H}_{2} \mathrm{~S}$ to thiosulphate, a non-toxic compound when oxygen is available (Jahn and Theede 1997). It is also suggested that $\mathrm{H}_{2} \mathrm{~S}$ can be bound as metal-sulphur precipitations in vesicles in the mantle edge (Jahn and Theede 1997). It is clear that the ability to handle toxic compounds, which add up as hypoxia recurs (Villnäs et al. 2013), will determine the capacity for survival at an individual level. Overall, the IBR index showed that while the adults were already stressed after one pulse of hypoxia, recurring or prolonged hypoxic stress resulted in a deteriorated health of surviving individuals. The biochemical response was supported by our observations of behavioural change, i.e., stretched-out siphons, emergence on sediment surface and slower reburial rates. In accordance with our observations, Long et al. (2008) observed decreased burial depths of M. balthica within 72 hours of the onset of hypoxia, well before a large-scale mortality occurred. The increased 
divergence from normal behaviour due to recurring hypoxic stress was confirmed by the gradual reductions in reburial rates. Similarly to our results, Tallqvist (2001) reported that adult M. balthica exposed to 13 days of hypoxia in laboratory conditions had both a later and slower burial compared to undisturbed individuals. The depressed burying depth, along with slow reburial rates will make these bivalves easily available to predators, such as fish or crustaceans (Norkko and Bonsdorff 1996a, b, Tallqvist 2001, Long et al. 2008, personal observations) which is likely to be an important factor for structuring the size distribution of bivalve populations exposed to pulses of hypoxic stress.

Distinct demographic changes were observed as hypoxia progressed. Juvenile bivalves survived one pulse (3 days) of hypoxia but were then reduced in numbers as hypoxia recurred. In contrast to our results, Jansson et al. (2015) showed, in laboratory conditions, that young $M$. balthica exposed to hypoxic conditions (ca $3.0 \mathrm{mg} \mathrm{O}_{2} \mathrm{ml}^{-1}$ ) during 29 days exhibited no reductions in overall activity and had even higher growth and survival rates compared to juveniles exposed to saturated oxygen concentrations. The improved survival rates were attributed to metabolic depression (Jansson et al. 2015). On the other hand, Norkko et al. (2005) showed a high mortality of juveniles of the bivalve Paphies australis exposed to hypoxic conditions (20\% saturation) during 10 days, while juvenile bivalves in treatments with oxygen saturation $>40 \%$ survived. Interestingly, in such circumstances, food availability had a more pronounced impact on the condition indices, scope for growth and nucleic acid ratios of the bivalves than did the low oxygen concentrations (Norkko et al. 2005). A limitation in food ability can be considered as an additional stressor for M. balthica in this study, as Villnäs et al. (2013) showed that microphytobenthic biomass was gradually degraded due to the recurring hypoxic stress and dark conditions introduced by the plastic. Indeed, in our field experiment, the combined effect of stressors (e.g., recurring oxygen deficiency, production and accumulation of toxic compounds $\left[\mathrm{NH}_{4}{ }^{+}, \mathrm{H}_{2} \mathrm{~S}\right]$, limitation of food sources as well as predation) that occur in natural environmental conditions is likely to have a more severe impact on survival rates than any single variable in isolation, and it is clear that the juveniles had a lower survival capability than the adults. In line with our observations, Vaquer-Sunyer and Duarte (2008) found significant ontogenetic shifts in survival time for marine benthic organisms when performing a meta-analysis identifying their hypoxic thresholds. The authors reported that early stages can have survival times of $64 \%$ compared to those of more developed ones when exposed to median lethal oxygen concentrations ( $\mathrm{LC}_{50}$; Vaquer-Sunyer and Duarte 2008).

In contrast to the juveniles, adult bivalves showed reduced abundance and biomass first after five recurring pulses of hypoxia while a peculiar rise in biomass were noted in the R1 and 
435 R3 treatments compared to the control. However, this pattern is in line with observations of Norkko 436 and Bonsdorff (1996a) who showed that the biomass of M. balthica was significantly higher in 437 sediments covered during 3 and 9 days by drifting algae, compared to undisturbed sediments. They 438 attributed the increased biomass to large bivalves emerging to the surface, initially too deep in the sediment for sampling. In line with our observations, the bivalve communities in the study above showed a complete crash in response to prolonged hypoxic stress (23 and 29 days; Norkko and

441 Bonsdorff 1996a). It is clear that the buffering capacity of the benthic ecosystem to oxygen

442 deficiency is reduced with recurring hypoxia (expressed as a reduction in available electron 443 acceptors and sediment bioturbation depth), which increases the susceptibility of the ecosystem to 444 move towards an anaerobic state (cf. Villnäs et al. 2013). Even though the sediment in our case had 445 four days to recover between the short pulses of hypoxia, the time was apparently not enough for 446 the recovery of the bivalve population or sediment biogeochemical conditions.

The recolonization success of $M$. balthica after disturbance ceases is likely to show strong size-dependency (Norkko et al. 2001, Villnäs et al. 2011, Norkko et al. 2013). Juvenile $M$. balthica are able to recolonize previously hypoxic sediments when conditions improve and food availability increases (van Colen et al. 2008). Although the juveniles might exhibit an opportunistic 451 peak in their response, they are among the later successional species (van Colen et al. 2008). 452 Importantly, adult bivalves are even slower to recover, as their colonization is likely to occur by 453 random redistribution through sediment transport and resuspension (Norkko and Bonsdorff 1996a). 454 Norkko et al. (2013) found that the adult fraction of $M$. balthica failed to recover one year after a 455 hypoxic event. That the recovery of bivalve populations can take months to years has ramifications 456 for the functioning of marine ecosystems, as these bivalves significantly contribute to ecosystem 457 functions and services (Bonsdorff et al. 1995, Michaud et al. 2005, 2006, Norkko et al. 2013).

459 changes (as indicated by biomarkers) precede alterations in population demography, and such 460 changes can serve as an early warning signal of hypoxic stress. Our results show that as the stress 461 response increases with recurring hypoxia, additional levels of organization are affected. 462 Consequently, evaluations of population health would benefit from utilizing a combination of 463 measures at different levels of organization (e.g. indicators of ROS damage, biomarkers, 464 behavioural observations and demographic change) so that disturbances to the ecosystem could be 465 detected at an early stage. This would enable an evaluation of the health, resistance and resilience of 466 important key species, and hence, of their contribution to ecosystem functioning in a marine 467 environment that is increasingly affected by anthropogenic change. 
468

\section{5. Acknowledgements}

470 We thank J. Norkko, S. Valanko, and A. Jansson for assistance with field work and A. Nevala, N.

471 Kinnunen and R. Turja for help with laboratory analyses. We are grateful to Tvärminne Zoological

472 Station for providing excellent research facilities. This study was funded by the BONUS + projects

473 HYPER and COCOA projects, supported by BONUS (Art 185), funded jointly by EU and the

474 Academy of Finland, by the Sophie von Julins Stiftelse and the Academy of Finland (project

475 294853).

476

477 


\section{References}

Aarnio, K., Bonsdorff, E., 1993. Seasonal variation in abundance and diet of the sand goby Pomatoschistus minutus (Pallas) in a northern Baltic archipelago. Ophelia 37, 19-30.

Andersson, M.J., Gorley, R.N., Clarke, K.R., 2008. PERMANOVA+ for PRIMER: Guide to software and statistical methods. PRIMER-E: Plymouth UK. 214 pp.

Barda, I., Purina, I., Rimsa, E., Balode, M., 2014. Seasonal dynamics of biomarkers in infaunal clam Macoma balthica from the Gulf of Riga (Baltic Sea). J. Mar. Syst. 129, 150-156.

Beliaeff, B., Burgeot, T., 2002. Integrated biomarker response: a useful tool for ecological risk assessment. Environ. Toxicol. Chem. 21, 1316-1322.

Bocquené, G., Galgani, F., 1998. Biological effects of contaminants: cholinesterase inhibition by organophosphate and carbamate compounds. ICES Tech. Mar. Environ. Sci. 22, 12 pp.

Bonsdorff, E., Norkko, A., Boström, C., 1995. Recruitment and population maintenance of the bivalve Macoma balthica (L.) - factors affecting settling success and early survival on shallow sandy bottoms. Biology and ecology of shallow coastal waters. Olsen \& Olsen, Fredensborg. pp. 253-260.

Bradford, M., 1976. A rapid and sensitive method for the quantitation of microgram quantities of protein utilizing the principle of protein-dye binding. Anal. Biochem. 72, 248-254.

Broeg, K., Lehtonen, K., 2006. Indices for the assessment of environmental pollution of the Baltic Sea coasts: Integrated assessment of a multi-biomarker approach. Mar. Pollut. Bull. 53, 508-522.

Caddy, J.F., 1967. Maturation of gametes and spawning in Macoma balthica (L.). Can. J. Zool. 45, 955-965.

Caddy, J.F., 1969. Development of mantle organs, feeding, and locomotion in postlarval Macoma balthica (L.) (Lamellibranchiata). Can. J. Zool. 47, 609-617.

Carlberg, I., Mannervik, B., 1975. Purification and characterization of flavoenzyme glutathione reductase from rat liver. J. Biol. Chem. 250, 5475-5480.

Carstensen, J., Conley, D.J., Bonsdorff, E., Gustafsson, B.G., Hietanen, S., Janas, U., Jilbert, T., Maximov, A., Norkko, A., Norkko, J., Reed, D.C., Slomp, C.P., Timmerman, K., Voss, M., 2014. Hypoxia in the Baltic Sea: Biogeochemical cycles, benthic fauna, and management. AMBIO 43, 26-36.

Claiborne, A., 1985. Catalase activity. In: Greenwald, R.A., (Ed.), Handbook of Methods for Oxygen Radical Research. CRC Press, Boca Raton, pp. 283-284.

Conley, D.J., Carstensen, J., Vaquer-Sunyer, R., Duarte, C.M., 2009. Ecosystem thresholds with hypoxia. Hydrobiologia 629, 21-29.

Conley, D.J., Carstensen, J., Aigars, J., Axe, P., Bonsdorff, E., Eremina, T., Haahti, B.-M., Humborg, C., Jonsson, P., Kotta, J., Lännegren, C., Larsson, U., Maximov, A., Medina, M.R., Lysiak-Pastuszak, E., Remeikaite-Nikiené, N., Walve, J., Wilhelms, S., Zillen, L., 2011. 
Hypoxia is increasing in the coastal zone of the Baltic Sea. Environ. Sci. Technol. 45, 67776783.

Diaz, R.J., Rosenberg, R., 1995. Marine benthic hypoxia: a review of its ecological effects and the behavioural responses of benthic macrofauna. Oceanogr. Mar. Biol. Annu. Rev. 33, 245-303.

Ellman, G.L., Courtney, D., Andres, Jr. V., Featherstone, R.M., 1961. A new and rapid colorimetric determination of acetylcholinesterase activity. Biochem. Pharmacol. 7, 88-90.

Fernandez, B., Campillo, J.A., Martinez-Gomez, C., Benedicto, J., 2010. Antioxidant responses in gills of mussel (Mytilus galloprovincialis) as biomarkers of environmental stress along the Spanish Mediterranean coast. Aquat. Toxicol. 99, 186-197.

Gilbert, M.A., 1973. Growth rate, longevity and maximum size of Macoma Balthica (L.). Biol. Bull. 145, 119-126.

Gray, J.S., Wu, R.S.S., Or, Y.Y., 2002. Effects of hypoxia and organic enrichment on the coastal marine environment. MEPS 238, 249-279.

Gorokhova, E., Löf, M., Reutgard, M., Lindström, M., Sundelin, B., 2013. Exposure to contaminants exacerbates oxidative stress in amphipod Monoporeia affinis subjected to fluctuation hypoxia. Aquat. Toxicol. 127, 46-53.

Guppy, M., Withers, P., 1999. Metabolic depression in animals: physiological perspectives and biochemical generalizations. Biol. Rev. Camb. Philos. Soc. 74, 1-40.

Habig, W.H., Pabst, M.J., Jakoby, W.B., 1974. Glutathione S-transferases - first enzymatic step in mercapturic acid formation. J. Biol. Chem. 249, 7130-7139.

Hermes-Lima, M., Zenteno-Savín, T., 2002 Animal response to drastic changes in oxygen availability and physiological oxidative stress. Comp. Biochem. Physiol. C 133, 537-556.

Hummel, H., Bogaards, R.H., Amiard-Triquetb, C., Bachelet, G., Desprezd, M., Marchand, J., Rybarczykd, H., Sylvand, B., de Wit, Y., de Wolf, L., 1995. Uniform variation in genetic traits of a marine bivalve related to starvation, pollution and geographic clines. JEMBE 191, 133-150.

Hummel, H., Bogaards, R.H., Bek, T., Polishchuk, L., Amiard-Triquet, C., Bachelet, G., Desprez, M., Strelkov, P., Sukhotin, A., Naumov, A., Dahle, S., Denisenko, S., Gantsevich, M., Sokolov, K., de Wolf, L., 1997. Sensitivity to stress in the bivalve Macoma balthica from the most northern (Arctic) to the most southern (French) populations: low sensitivity in Arctic populations because of genetic adaptations? Hydrobiologia 355, 127-138.

Jahn, A., Theede, H., 1997. Different degrees of tolerance to hydrogen sulphide in populations of Macoma balthica (Bivalvia, Tellinidae). MEPS 154, 185-196.

Jansson, A., Norkko, J., Dupont, S., Norkko, A., 2015. Growth and survival in a changing environment: Combined effects of moderate hypoxia and low $\mathrm{pH}$ on juvenile bivalve Macoma balthica. J. Sea Res. 102: 41-47. 
Karlson, K., Rosenberg, R., Bonsdorff, E., 2002 Temporal and spatial large-scale effects of eutrophication and oxygen deficiency on benthic fauna in Scandinavian and Baltic waters: A review. Oceanogr. Mar. Biol. 40, 427-489.

Khan, B., Ringwood, A., 2016. Cellular biomarker responses to hypoxia in eastern oysters and Atlantic ribbed marsh mussels. MEPS 546, 123-133.

Lam, P.K.S., Gray, J.S., 2003. The use of biomarkers in environmental monitoring programmes. Mar. Pollut. Bull. 46, 182-186.

Lehtonen, K.K., Leiniö, S., Schneider, R., Leivuori, M., 2006. Biomarkers of pollution effects in the bivalves Mytilus edulis and Macoma balthica collected from the southern coast of Finland (Baltic Sea). MEPS 322, 155-168.

Leiniö, S., Lehtonen, K., 2005. Seasonal variability in biomarkers in the bivalves Mytilus edulis and Macoma balthica from the northern Baltic Sea. Comp. Biochem. Physiol. C 140, 408-421.

Levin, L.A., Ekau, W., Gooday, A.J., Jorissen, F., Middelburg, J.J., Naqvi, S.W.A., Neira, C., Rabalais, N.N., Zhang, J., 2009. Effects of natural and human-induced hypoxia on coastal benthos. Biogeosciences 6, 2063-2098.

Livingstone, D.R., 2001. Contaminant-stimulated reactive oxygen species production and oxidative damage in aquatic organisms. Mar. Pollut. Bull. 42, 656-666.

Long, W.C., Brylawski, B.J., Seitz, R.D., 2008. Behavioural effects of low dissolved oxygen on the bivalve Macoma balthica. JEMBE 359, 34-39.

Lushchak, V.I., 2011. Environmentally induced oxidative stress in aquatic animals. Aquat. Toxicol. 101, 13-30.

Michaud, E., Desrosiers, G., Mermillod-Blondin, F., Sundby, B., Stora, G., 2005. The functional group approach to bioturbation: The effects of biodiffusers and gallery-diffusers of the Macoma balthica community on sediment oxygen uptake. JEMBE 326, 77-88.

Michaud, E., Desrosiers, G., Mermillod-Blondin, F., Sundby, B., Stora, G., 2006. The functional group approach to bioturbation: II. The effects of the Macoma balthica community on fluxes of nutrients and dissolved organic carbon across the sediment-water interface. JEMBE 337, 178189.

Modig, H., Ólafsson, E., 1998. Responses of Baltic benthic invertebrates to hypoxic events. JEMBE $229,133-148$.

Nikula, R., Strelkov, P., Väinölä, R., 2008. A broad transition zone between an inner Baltic hybrid swarm and pure North Sea subspecies of Macoma balthica (Mollusca, Bivalvia). Mol. Ecol. 17, $1505-1522$.

Norkko, A., Bonsdorff, E., 1996a. Population responses of coastal zoobenthos to stress induced by drifting algal mats. MEPS 140, 141-151.

Norkko, A., Bonsdorff, E., 1996b. Altered benthic prey-availability due to episodic oxygen deficiency caused by drifting algal mats. Mar. Ecol. 17: 355-372. 
Norkko, A., Cummings, V.J., Thrush, S.F., Hewitt, J.E., Hume, T., 2001. Local dispersal of juvenile bivalves: implications for sandflat ecology. MEPS 212, 131-144.

Norkko, J., Pilditch, C.A., Thrush, S.F., Wells, R.M.G., 2005. Effects of food availability and hypoxia on bivalves: the value of using multiple parameters to measure bivalve condition in environmental studies. MEPS 298, 205-2118.

Norkko, A., Villnäs, A., Norkko, J., Valanko, S., Pilditch, C., 2013. Size matters: implications of the loss of large individuals for ecosystem function. Sci. Rep. 3, 2646.

Philipp, E.E.R., Wessels, W., Gruber, H., Strahl, J., Wagner, A.E., Ernst, I.M., Rimbach, G., Kraemer, L., Schreiber, S., Abele, D., Rosenstiel, P., 2012. Gene expression and physiological changes of different populations of the long-lived bivalve Arctica islandica under low oxygen conditions. PLoS ONE 7(9): e44621. doi:10.1371/journal.pone.0044621

Regoli, F., Giuliani, M.E., 2014. Oxidative pathways of chemical toxicity and oxidative stress biomarkers in marine organisms. Mar Environ Res. 93, 106-17.

Riedel, B., Zuschin, M., Haselmair, A., Stachowitsch, M., 2008. Oxygen depletion under glass: Behavioural response of benthic macrofauna to induced anoxia in the Northern Adriatic. JEMBE 267, 17-27.

Rivera-Ingraham GA, Rocchetta I, Meyer S, Abele D. 2013. Oxygen radical formation in anoxic transgression and anoxia-reoxygenation: Foe or phantom? Experiments with a hypoxia tolerant bivalve. Mar. Env. Res. 92: 110-119.

Segerstråle, S.G., 1960. Investigations on Baltic populations of the bivalve Macoma baltica (L.). Part I. Introduction. Studies on recruitment and its relation to depth in Finnish coastal waters during the period 1922-1959. Age and growth. Soc. Scient. Fenn. Comm. Biologicae 23, 1-72.

Segerstråle, S.G., 1965. Biotic factors affecting the vertical distribution and abundance of the bivalve, Macoma baltica (L.), in the Baltic Sea. Botanica Gothoburgensia III, 195-204.

Sussarellu R, Fabioux C, Sanchez MC, Le Goïc N, Lambert C, Soudant P, Moraga D. 2012. Molecular and cellular response to short-term oxygen variations in the Pacific oyster Crassostrea gigas. JEMBE 412:87-95.

Tallqvist, M., 2001. Burrowing behaviour of the Baltic clam Macoma balthica: effects of sediment type, hypoxia and predator presence. MEPS 212, 183-191.

Turja, R., Soirinsuo, A., Budzinski, H., Devier, M.H., Lehtonen, K., 2013. Biomarker responses and accumulation of hazardous substances in mussels (Mytilus trossulus) transplanted along a pollution gradient close to an oil terminal in the Gulf of Finland (Baltic Sea). Comp. Biochem. Physiol. C 157, 80-92.

Valanko, S., Norkko, A., Norkko, J., 2010. Strategies of post-larval dispersal in non-tidal softsediment communities. JEMBE 384, 51-60.

van Colen, C., Monserrat, F., Vincx, M., Herman, P.M.J., Ysebaert, T., Degraer, S., 2008. Macrobenthic recovery from hypoxia in an estuarine tidal mudflat. MEPS 372, 31-42. 
Vaquer-Sunyer, R., Duarte, C.M., 2008. Thresholds of hypoxia for marine biodiversity. PNAS 105, $15452-15457$.

Villnäs, A., Perus, J., Bonsdorff, E., 2011. Structural and functional shifts in zoobenthos induced by organic enrichment- implications for community recovery potential. J. Sea Res. 65, 8-18.

Villnäs, A., Norkko, J., Lukkari, K., Hewitt, J., Norkko, A., 2012. Consequences of increasing hypoxic disturbance on benthic communities and ecosystem functioning. PLoS ONE 7: 1-12.

Villnäs, A., Norkko, J., Hietanen, S., Josefson, A.B., Lukkari, K., Norkko, A., 2013. The role of recurrent disturbances for ecosystem multifunctionality. Ecology 94, 2275-2287.

Volkenborn, N., Meile, C., Polerecky, L., Pilditch, C.A., Norkko, A., Norkko, J., Hewitt, J.E., Thrush, S.F., Wethey, D.S., Woodin, S.A., 2012. Intermittent bioirrigation and oxygen dynamics in permeable sediments: An experimental and modeling study of three tellinid bivalves. J. Mar. Res. 70, 794-823.

Welker, A.F., Moreira, D.C., Campos, É.G., Hermes-Lima, M., 2013. Role of redox metabolism for adaptation of aquatic animals to drastic changes in oxygen availability. Comp. Biochem. Physiol. A $165,384-404$.

Wu, R.S.S., 2002. Hypoxia: from molecular responses to ecosystem responses. Mar. Pollut. Bull. $45,35-45$.

Yusseppone MS, Rocchetta I, Sabatini SE, Luquet CM, Rios de Molina MdC, Held C, Abele D. 2018. Inducing the alternative oxidase forms part of the molecular strategy of anoxic survival in freshwater bivalves. Front. Pysiol. 9. doi: 103389/fphys.2018.00100

Zenteno-Savín. T., Saldierna. R., Ahuejote-Sandoval, M., 2006. Superoxide radical production in response to environmental hypoxia in cultured shrimp. Comp. Biochem. Physiol. C 142, 301-308. 
648 Table 1. Permutational ANOVA describing differences between treatments of recurring hypoxia.

649 For measures of reburial rates and demography, the L treatment (30 days of uninterrupted hypoxia)

650 was excluded from all analyses, as its impoverished (dead) population was clearly different from

651 the other treatments. Abbreviations: CAT; catalase, GR; glutathione reductase, GST; glutathione S652 transferase, AChE; acetylcholinesterase.

653

\begin{tabular}{l|rrrrr} 
PERMANOVA & df & \multicolumn{1}{c}{ SS } & MS & Pseudo-F & P(perm) \\
\hline Biomarkers & \multicolumn{5}{c}{} \\
$\quad$ CAT & 4 & 5975,5 & 1493,9 & 0,80 & 0,534 \\
GST & 4 & 592770,0 & 148190,0 & 0,84 & 0,509 \\
GR & 4 & 12,9 & 3,2 & 7,90 & 0,000 \\
AChE & 4 & 1229,7 & 307,4 & 3,54 & 0,013 \\
Reburial rates & 3 & 460,7 & 153,6 & 4,57 & 0,004 \\
$\begin{array}{l}\text { Demography } \\
\text { juv. abundance }\end{array}$ & 3 & 24470,0 & 8156,7 & 7,66 & 0,006 \\
$\quad$ juv. biomass & 3 & 2,7 & 0,9 & 7,66 & 0,005 \\
$\quad$ adult abundance & 3 & 179,2 & 59,7 & 9,82 & 0,003 \\
$\quad$ adult biomass & 3 & 42,2 & 14,1 & 5,30 & 0,016 \\
$\quad$ size structure & 3 & 18231,0 & 6076,8 & 4,15 & 0,002
\end{tabular}

655

656

657

658 

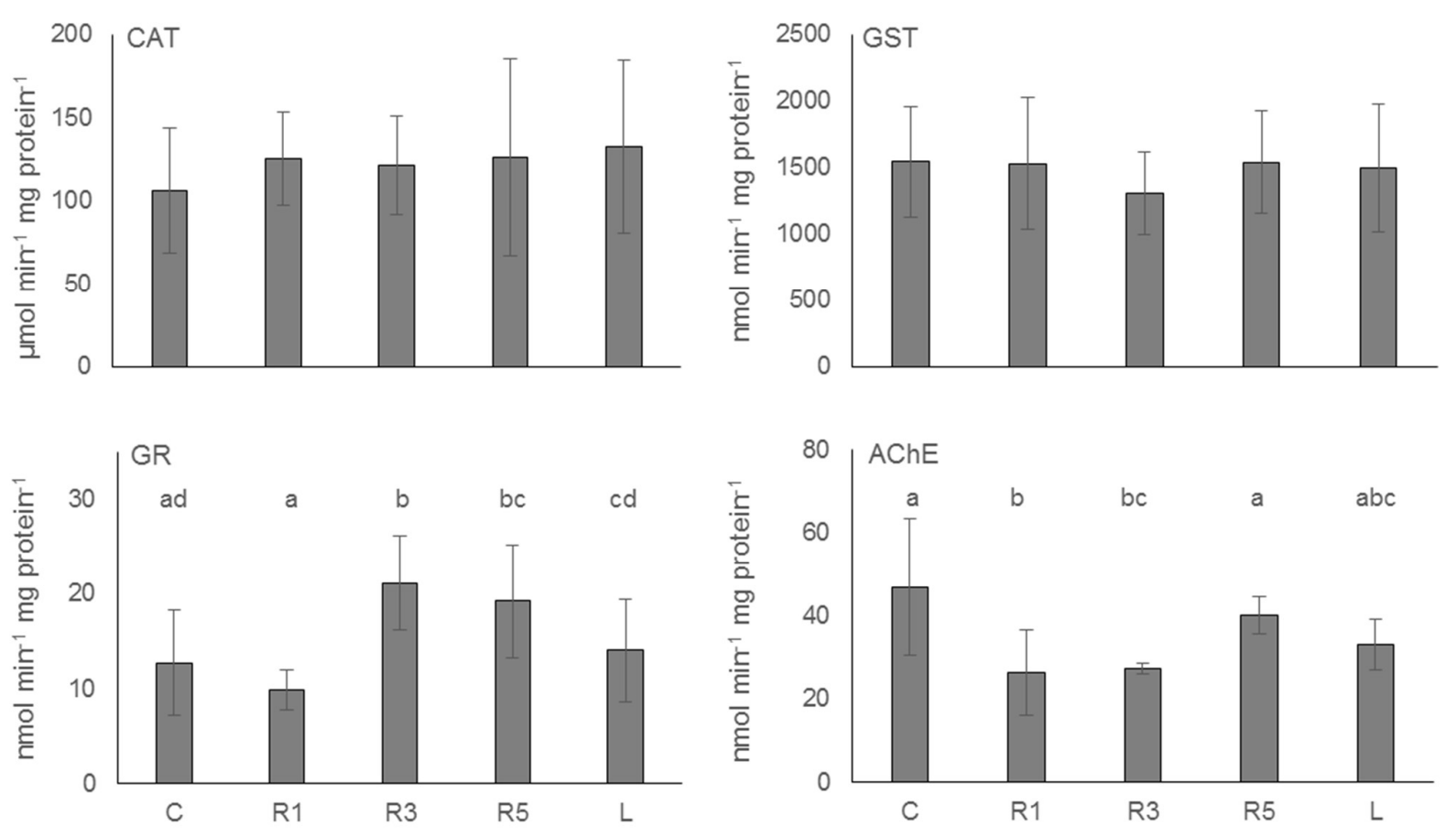

Figure 1. Catalase (CAT), glutathione reductase (GR), glutathione $S$-transferase (GST), and

661 acetylcholinesterase activity (AChE; avg. \pm std) in adult Macoma balthica exposed to increasingly

662 recurring hypoxic stress. Different letters denote significant $(p<0.05)$ post-hoc differences between

663 treatments. For acetylcholinesterase, post hoc comparisons between C-R1 and R1-R5 had a p-value 664 of 0.05 . 


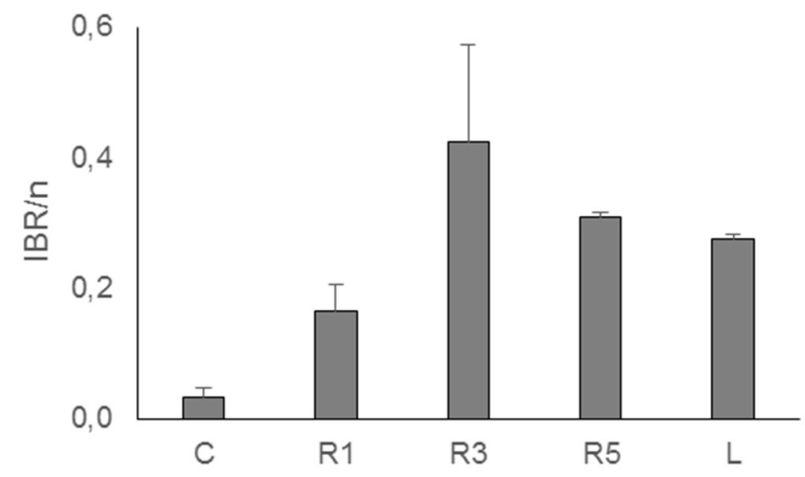

667 Figure 2. The Integrated Biomarker Index (IBR) represents the sum of standardized biomarker 668 values, divided by the number of biomarkers used (IBR/n).

669

670

671

672

673

674

675

676

677

678

679

680

681

682

683 

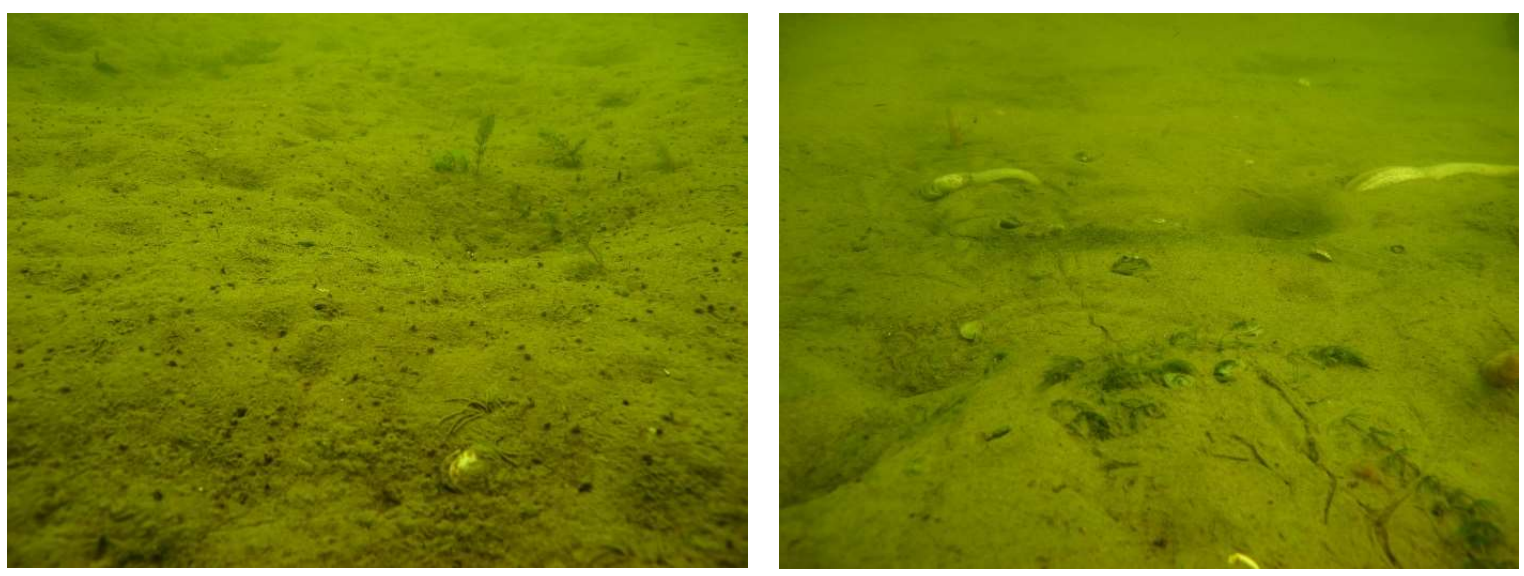

684

685 Figure 3. Undisturbed seafloor (left) and a sediment exposed to repeatedly occurring hypoxic stress 686 (right), where the black colour on the sediment is indicative of a precipitation of ferrosulphides 687 during anoxic conditions. Several bivalves have emerged to the sediment surface and extended their 688 siphons to escape the hypoxic stress. Photos by Alf Norkko. 


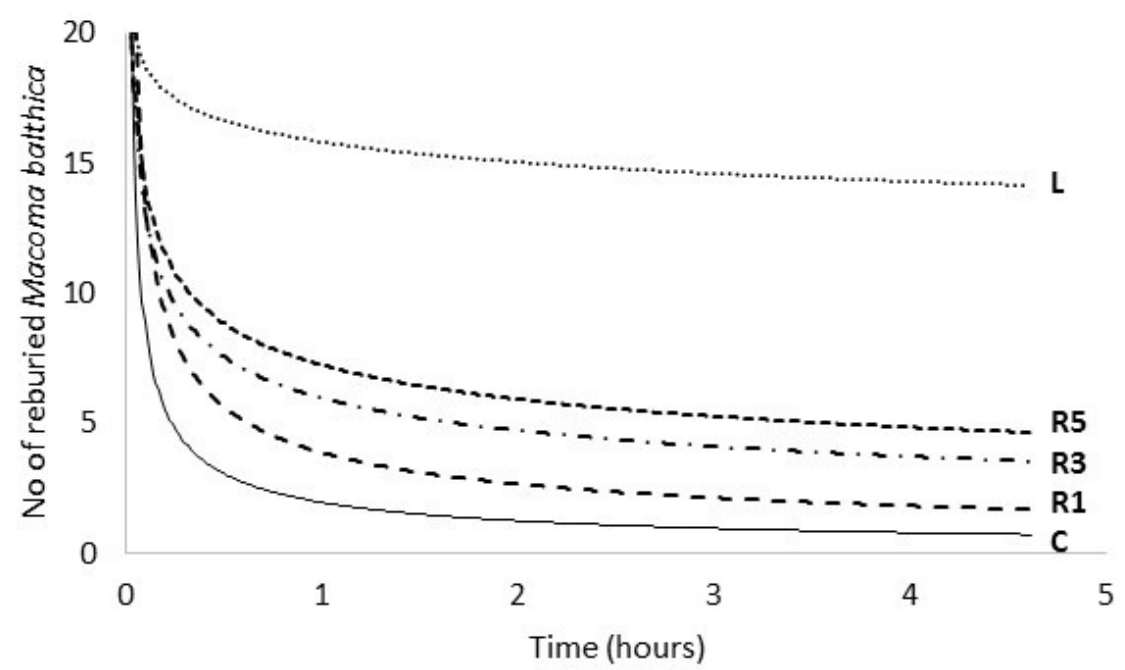

690

691 Figure 4. Reburial rates of adult Macoma balthica between different treatments. A power trendline 692 was fit to describe the response pattern in each treatment $\left(\mathrm{R}^{2}>0.75, \mathrm{p}<0.01\right)$. The total number of 693 Macoma was 20 in all treatments except for L, where only 10 individuals were used.

694

695

696

697

698

699

700

701

702

703

704

705

706

707

708 
709
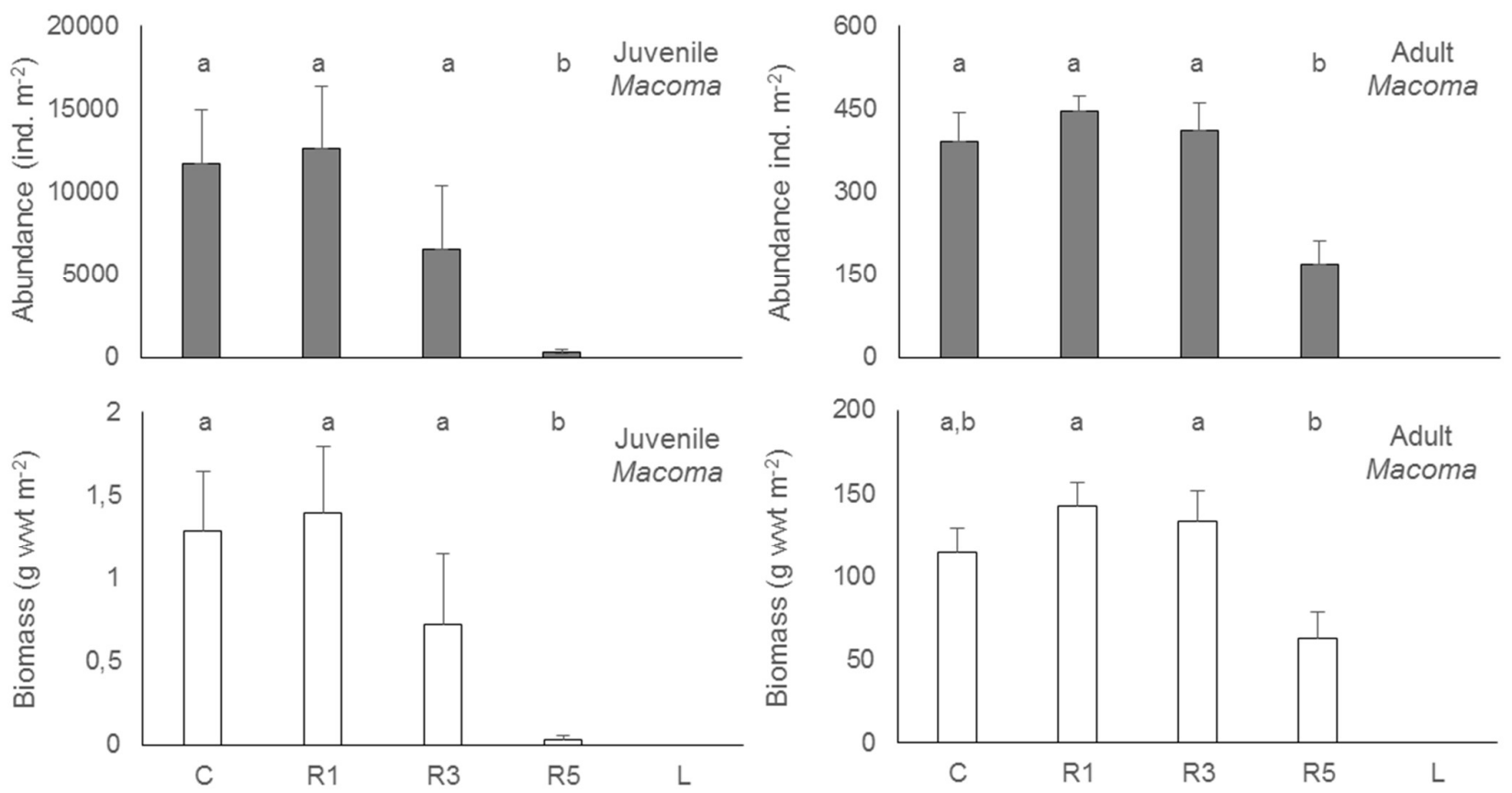

710

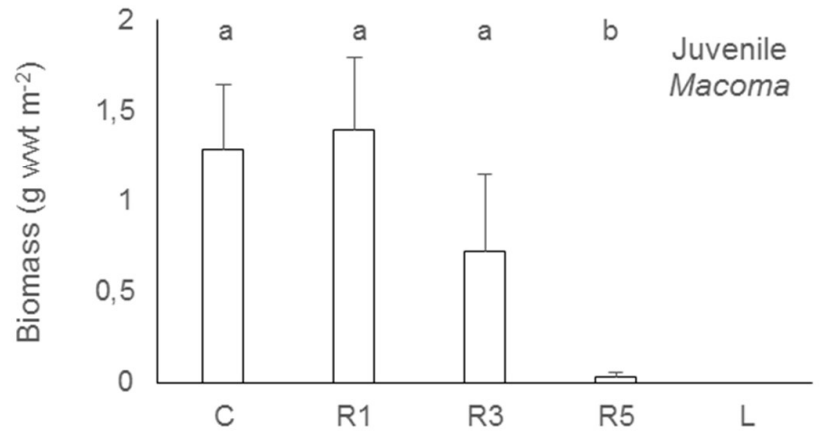

711 Figure 5. Total abundance (upper graphs) and biomass (lower graphs) per treatment (avg $\pm \mathrm{SE})$ of 712 juvenile and adult Macoma balthica. Note the different scales. Different letters denotes significant $713(\mathrm{p}<0.05)$ post-hoc differences between treatments.

714

715

716

717

718

719

720

721

722 

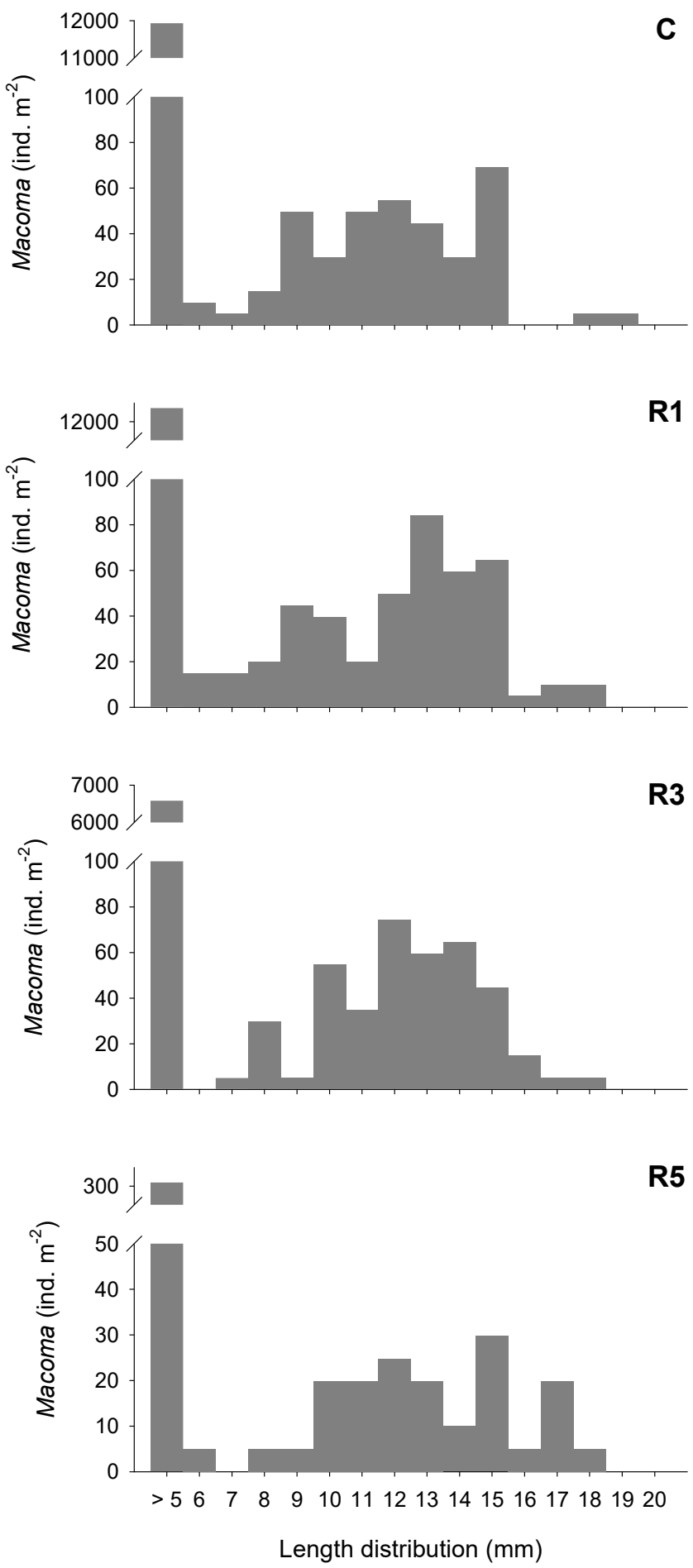

Figure 6. Length distribution of $M$. balthica in the $\mathrm{C}, \mathrm{R} 1, \mathrm{R} 3$ and $\mathrm{R} 5$ treatments. The size class of 5 $\mathrm{mm}$ represents bivalves less $\leq 5 \mathrm{~mm}$. Note the different scales on the y-axes. 